\title{
RACISMO E CONSTRUÇÃO IDENTITÁRIA DO SUJEITO HÍBRIDO EM AUTOBIOGRAFIA DE UM EX-NEGRO, DE JAMES WELDON JOHNSON
}

Leonardo Júnio Sobrinho Rosa (UFSJ)

Luiz Manoel da Silva Oliveira (UFSJ)

Resumo: Autobiografia de um ex-negro, de James Weldon Johnson (1871-1938), perpassa o período da segunda metade do século XIX (o momento posterior à Guerra Civil dos EUA [1861-1865]) e vai até o início do século XX. A obra narra a história de um personagem anônimo, em um entrelugar de culturas e espaços, vivenciando desde a infância as crueldades das questões étnico-raciais. Essa problemática é tão latente que leva o protagonista a passar por constantes processos de fragmentação e hibridismo cultural. Em virtude da relevância dessa obra, este trabalho busca analisar o processo de construção identitária do seu narrador-personagem, sendo que essa constituição se dá frente aos constantes deslocamentos dele pelos espaços geográficos, emocionais e interespaços identitários. Esse trânsito por distintos espaços leva o narrador a uma transformação de subjetividade, representada pela transição de "de branco a negro" e de "negro a exnegro". Além disso, a questão identitária revela o processo de formação de um sujeito híbrido multicultural. Assim, convém esclarecer que esse viés interpretativo guarda uma tangível relação com a segregação racial. Intenta-se demonstrar como a questão racial nos Estados Unidos foi pautada por muitas décadas desde aquela época por princípios de violência e objetificação direcionadas aos negros por meio de políticas respaldadas pelo sistema político e judiciário estadunidense. Antes do aprofundamento dessas questões, é apropriado elencar informações sobre o escritor, o romance e o movimento da Renascença do Harlem. Para alcançar os objetivos propostos, o presente trabalho utiliza como aporte crítico-teórico as contribuições de Bonnici (2009), Hall (1998 e 2003) e Said (2003), dentre outros.

Palavras-chave: Racismo; Segregação; Construção identitária; Sujeito híbrido; Multicultural.

Abstract: Autobiography of an ex-colored man, by James Weldon Johnson (1871-1938), permeates the historical period from 
mid-nineteen century up to the beginning of the $20^{\text {th }}$ century, the time from the American Civil War (1861-1865) on. This novel narrates the story of an anonymous character, who is in a cultural and spatial crossroads. From childhood, he experiences the cruelties arising from ethnic-racial relations. This problem is so remarkable that it makes the protagonist undergo constant processes of fragmentation and cultural hybridity. Given the relevance of Johnson's novel, the present work seeks to examine the identity building process of its narrator-character, which is constituted under the influence of his dislocations through geographical and emotional spaces, as well as his identitary interspaces. This transit leads the narrator to an identity transformation, ultimately epitomized by his transition from "white to colored" and then from "colored to ex-colored". In addition, the identity question exposes the process of formation of a hybrid and multicultural subject. Thus, it should be clarified that this interpretative prism has a tangible relation with racism and racial segregation. Our intention is to demonstrate how the racial question in the United States has been for so many decades based on principles of violence and objectification directed to black people thanks to a number of policies supported by the American political, cultural and judicial system. Before getting deeper into these questions, it is appropriate to provide information about the writer, the novel and the Harlem Renaissance. To reach the proposed objectives, the present work uses the contributions of Bonnici (2009), Hall (1998 and 2003), Said (2003), among others.

Keywords: Racism; Segregation; Identity building; Hybrid subject; Multicultural.

\section{INTRODUÇÃO}

Nos Estados Unidos, racismo e segregação racial constituem fatores inalienáveis das políticas de sujeição da população negra. Ambos, na maioria das vezes, encontravam respaldo nos sistemas político e jurídico estadunidenses. Isso acabou promovendo a manutenção desse status quo negativo, por muitas décadas e até um passado recente, com os seus ranços e rastros remanescentes até o presente momento. 
Visando à modificação desse cenário, surgiu a Renascença do Harlem: um movimento cultural, estético e político de forte caráter de subversão e resistência. Nesse momento de transformação, a cultura, a arte e a literatura afroestadunidenses - e demais formas de expressão - passam a caminhar para fora do gueto e adquirem visibilidade e reconhecimento.

Autobiografia de um ex-negro, de James Weldon Johnson (1871-1938), é um representante legítimo desse período de grande efervescência de novos ideais. O romance do escritor afro-estadunidense perpassa pelo período histórico da metade de século XIX e início do século $X X$, mais precisamente no momento posterior à Guerra Civil estadunidense (18611865). A referida obra narra a história de um personagem anônimo, que se encontra em um entrelugar de culturas e espaços. Ele vivencia, desde a sua infância, as crueldades oriundas das questões étnico-raciais. Essa problemática é tão latente na obra, que leva o protagonista a passar por constantes processos de fragmentação e hibridismo cultural.

Dada a relevância da obra de Johnson e das inúmeras leituras e interpretações visualizadas a partir dela, o presente trabalho busca analisar como ocorre o processo de construção identitária do narrador-personagem utilizado 
por Johnson, sendo que essa constituição se dá frente aos constantes deslocamentos pelos espaços geográficos e emocionais e interespaços identitários. Esse trânsito por distintos espaços leva o narrador a uma transformação identitária, representada pela sua transição de "negro a exnegro", como instigantemente é sugerido no título da obra de Johnson. Além disso, a questão identitária desvela o processo de formação de um sujeito híbrido e multicultural.

Nesse sentido, convém esclarecer que esse viés interpretativo guarda uma tangível relação com o racismo e a segregação racial. Desse modo, intenta-se demonstrar como a questão racial nos Estados Unidos, no período histórico em que a trama da obra se desenrola, foi pautada por princípios de violência e objetificação direcionadas aos negros, por meio de políticas praticadas por parte da sociedade, que, na maioria das vezes, encontra respaldo nos sistemas político e judiciário da nação estadunidense. Contudo, antes do aprofundamento dessas questões, é conveniente elencar informações sobre o escritor, o romance e o movimento da Renascença do Harlem. Para alcançar os objetivos, o presente trabalho utiliza como aporte crítico-teórico as contribuições de Edward Said (2003), Stuart Hall (1998 e 2003) e Thomas Bonnici (2009), dentre outros estudiosos. 


\section{RACISMO E SEGREGAÇÃO NOS ESTADOS UNIDOS}

Na contemporaneidade, racismo e segregação podem ser compreendidos como um tipo de política elaborada por um governo, partido político, empresa ou organização que objetiva a separação de indivíduos ou grupos de uma determinada sociedade por meio de critérios raciais ou étnicos. Esses tipos de medida estabelecem "fronteiras arbitrárias, separando os grupos entre si e julgando as pessoas intrinsecamente de acordo com certas características consideradas favoráveis ou desfavoráveis" (PACHECO, 1983, p.7). Eles marcaram fortemente a história ocidental, uma vez que possibilitaram o surgimento do antissemitismo na Alemanha e o apartheid na África do Sul, por exemplo, assim como os demais movimentos segregacionistas pelo mundo afora.

Nos Estados Unidos, a questão racial é um problema antigo que ainda ecoa nos dias atuais. Ao retroceder historicamente, podemos observar que a situação da população negra estadunidense é o resultado de diversos fatores, como a diáspora imposta às populações de muitos países de África pelas potências daquele período e os horrores oriundos do sistema escravagista, que acabou por se tornar uma instituição sólida naquele país. 
Aescravidão necessitava de apoio político ejurídico, a fim de consolidar e manter seu funcionamento. Consequentemente, houve uma série de leis e regulamentações, as quais tinham como objetivos controlar as ações dos negros e defender a escravatura ${ }^{3}$. A mudança mais significativa desse status quo veio com a Guerra Civil, que promulgou o fim oficial da escravidão. Para Francisco Bethencourt, "a definitiva abolição da escravatura nos Estados Unidos (1865) marcou o fim do comércio escravagista interno e pressagiou o fim da escravatura nas Américas" (2018, p.406).

Josephine Pacheco (1983), ao analisar o término da escravidão, explicita que esta

não significou o fim de preconceitos racistas dos brancos com relação aos negros. Não significou tampouco que os escravos libertos tivessem os recursos necessários para agir independentemente. Ninguém no país, nem no Norte nem no Sul, preocupouse seriamente com o problema de como aqueles libertos poderiam sobreviver. [...] Por conseguinte, os libertos tiveram em geral que retornar ao único ofício que conheciam, a saber, o trabalho agrícola, e em muitos casos foram obrigados a trabalhar de novo para os seus antigos senhores. Assim, verificaram que eram livres juridicamente, mas sob o ponto de vista econômico a sua situação não era muito melhor que a que tiveram quando escravos. (p.48) 
O período posterior à Guerra Civil nos EUA é conhecido historicamente como "Reconstrução" justamente porque marca a unificação/reconstrução da nação e a reincorporação dos estados sulistas ao restante do país. Naquele momento, começaram a surgir as primeiras tentativas de implementação de políticas segregacionistas. A população negra foi perdendo continuamente os seus escassos direitos: "encontravam franca discriminação em tudo que desejavam fazer e tinham, além disso, que arrostar os obstáculos de extrema miséria e péssimas condições de ensino, e bem assim os implacáveis preconceitos dos brancos" (PACHECO, 1983, p.50-51).

Acerca do processo de implementação de políticas segregacionistas, Leandro Karnal (2007) nos informa que:

Leis de segregação racial haviam feito breve aparição durante a Reconstrução, mas desapareceram até 1868. Ressurgiram no governo de Grant, a começar pelo Tennessee, em 1870: lá, os sulistas brancos promulgaram leis contra o casamento interracial. Cinco anos mais tarde, o Tennessee adotou a primeira Lei Jim Crow e o resto do sul o seguiu rapidamente. O termo 'Jim Crow', nascido de uma música popular, referia-se a toda lei (foram dezenas) que seguisse o princípio 'separados, mas iguais', estabelecendo afastamento entre negros e brancos nos trens, estações ferroviárias, cais, hotéis, barbearias, restaurantes, teatros, entre outros. Em 1885, a maior 
parte das escolas sulistas também foram divididas em instituições para brancos e outras para negros. Houve 'leis Jim Crow' por todo o sul. Apenas nas décadas de 1950 e 1960 a suprema Corte derrubaria a ideia de 'separados, mas iguais. (p.145)

Os entraves sociais produzidos pelas políticas de segregação e pela virulência do racismo somente começariam a ser parcialmente resolvidos com os movimentos pelos direitos civis dos negros na década de 1960. Entretanto, deve-se destacar a participação de figuras históricas, como a poetisa negra (de início escravizada) Phillis Wheatley (17531784) e o ativista e escritor Frederick Douglass (1818-1895), que, na medida do possível, dado o contexto de opressão e silenciamento das épocas em que viveram, opuseram resistência frente às situações de agrura vivenciadas pelos seus irmãos negros nos Estados Unidos.

Tanto o racismo quanto a segregação foram instituídos como um projeto político-social, que visava à criação e reprodução de estruturas de dominação, que se baseiam em questões raciais. Essas estruturas eram aceitas sem qualquer tipo de reflexão crítica, o que possibilitou a organização das instituições que compõem a sociedade estadunidense e a manutenção de um sistema discriminatório e excludente. Mesmo com os avanços ocorridos com os movimentos 
que buscavam os direitos civis, aqui e ali, os negros só passaram a ter um lugar de destaque no cenário estadunidense com a Renascença do Harlem.

\section{A OBRA DE JAMES WELDON JOHNSON E O MOVIMENTO DA RENASCENÇA DO HARLEM}

O período histórico compreendido entre os anos de 1920 e 1930 é caracterizado por um momento de grande efervescência nos Estados Unidos. Quebrando parâmetros e paradigmas, artistas, ativistas e intelectuais afro-estadunidenses se uniram e compuseram o Harlem Renaissance (Renascença do Harlem): um movimento político, artístico e cultural, que visava a modificar as estruturas vigentes da época, as quais fomentavam a subalternização da população negra estadunidense.

Essa atmosfera promissora da Renascença do Harlem fez com que as produções da lavra de autores, autoras e artistas afro-estadunidenses saíssem do gueto e ganhassem a devida visibilidade e reconhecimento. Não obstante, "o movimento da Renascença é também uma forma de recuperação de uma identidade negra dizimada por séculos de escravidão e discriminação racial" (HATTNHER, 1992, p.60).

A Literatura difundida durante esse período articula em seu cerne referências culturais e políticas que vão desde 
o período da escravidão e reverberam nos dias atuais, "desde pioneiros da negritude e denunciadores da opressão, como Hughes e DuBois, até a atuação política renovadora de líderes como Martin Luther King e Malcom X" (TOMÉ, 2016, p.120), assim como "[...] até uma poesia oral recitada nos guetos urbanos metropolitanos na cultura negra contemporânea do 'hip-hop'” (TOMÉ, 2016, p.120).

Dentre as inúmeras obras de grande relevância do período, destacamos Autobiografia de um ex-negro (Autobiography of an ex-colored man, em inglês). Republicada nesse período de grande pujança, o romance de James Weldon Johnson fornece sua valorosa contribuição à Renascença do Harlem ao demonstrar todo o seu pioneirismo em retratar de maneira extremamente peculiar a segregação racial, evidenciando, assim, a perversidade, a crueldade e as violências advindas do preconceito racial nos Estados Unidos, visto que a temática principal que afeta o protagonista "do romance refere-se ao drama experimentado por pessoas aparentemente brancas, mas que, por terem porcentagem mínima de sangue negro, passam a ser objeto de opressão e segregação por parte de brancos e negros simultaneamente" (OLIVEIRA, 2015, p.298).

O romance de estreia de Johnson apresenta traços distintivos de uma grande obra, pois transcende a mera 
categorização de um estudo sociológico, conforme foi anunciado na primeira publicação sob pseudônimo (1912). Observa-se, também, o vanguardismo dessa obra de Johnson por se tratar de um romance travestido de autobiografia. Esse testemunho de tom "autobiográfico", juntamente com suas temáticas singulares, gera "uma rede intertextual admirável, já que outras obras foram subsequentemente lançadas seguindo o seu rastro temático" (OLIVEIRA, 2015, p.299).

Dessa maneira, escritor e obra são de enorme relevância dentro do contexto da Renascença do Harlem. É notório que artistas e intelectuais negros tiveram uma participação efetiva e marcante para o movimento, como Claude McKay, Jean Toomer e Langston Hughes, dentre outros. A Renascença do Harlem, ao reunir homens e mulheres de diversas partes dos Estados Unidos, possibilitou 0 reconhecimento da rica herança cultural, artística, musical e literária afro-estadunidense, que estava destinada aos espaços da invisibilidade e da marginalização.

\section{CONSTRUÇÃO IDENTITÁRIA EM AUTOBIOGRAFIA, DE JAMES WELDON JOHNSON}

James Weldon Johnson, em Autobiografia de um exnegro, expõe ao leitor a vida cotidiana da população negra estadunidense a partir do olhar da figura de um homem comum: um anti-herói detentor de traços fenotípicos 
que Ihe permitem se passar por uma pessoa branca. Contudo, ele apresenta uma porcentagem de sangue negro em suas veias, devido ao fato de sua mãe ser negra, fazendo-o, assim, questionar a qual grupo étnico ele pertencia de fato.

O protagonista de Johnson inicia seu relato pela infância. Nesse momento, ele tem seu primeiro contato com as duras políticas estadunidenses de segregação. Certa feita, na escola, a professora solicita que todas as crianças brancas se levantem. Ciente até aquele momento de seus traços de "branco", o protagonista acata a ordem recebida, mas é advertido pela professora para que volte a se sentar e que levante somente quando as crianças negras forem convidadas a isso. Ao final da aula, as crianças brancas afirmam: "Oh, você é um crioulo também" (JOHNSON, 2010, p.8), enquanto que as negras declaram que sabiam que ele é uma pessoa de cor. Esse trauma vivenciado na infância "marca a ferro" o narrador. Em suas palavras, ele afirma:

E assim tenho revivido muitas vezes aquela hora, aquele dia, aquela semana, na qual se descortinou o milagre de minha transição de um mundo para o outro - pois eu passei, de fato, a habitar outro mundo. A partir daquele instante, eu vi com outros olhos, meus pensamentos ganharam cor, minhas palavras eram ditadas e minhas ações limitadas por uma ideia dominante e onipresente que constantemente crescia 
em força e peso até eu me dar conta disso por meio de um fato importante e tangível. E essa é a influência que apequena, distorce e corrói o pensamento de cada homem de cor nos Estados Unidos. Ele é forçado a ver todas as coisas não a partir do ponto de vista de um cidadão, ou de um homem, sequer de um ser humano, mas do ponto de vista de um homem de cor. Para mim, é incrível nossa raça estar progredindo tão enormemente quando a maior parte de seu pensamento e todas as suas atividades passam pelo estreito funil de tais limitações. (JOHNSON, 2010, p.21-22)

Logo após esse episódio tão marcante, o narradorpersonagem passa a buscar pelas suas raízes e questiona a mãe sobre seu pai. Esse questionamento repentino do filho constrange a mãe, pois esta se vê obrigada a dizer que não é branca, mas sim negra. A mãe ainda tenta remediar a situação ao assegurar que o narrador é branco e que "seu pai é um dos homens mais importantes do país - o melhor sangue do sul está em você" (JOHNSON, 2010, p.19). O pai é uma figura forte, mas ausente, que faz uma repentina visita pouco antes da morte prematura da mãe.

Com o falecimento de sua mãe, o protagonista organiza um recital de piano com o objetivo de reunir fundos para viajar para a Universidade de Atlanta, onde deseja estudar. Ao sofrer um golpe em que Ihe são tiradas todas as suas 
economias, o narrador vê ruir o sonho de estudar em uma universidade. Assim, ele parte de Atlanta para Jacksonville, onde começa sua aventura burlesca e o mergulho no universo da cultura, da música e "das tradições de matriz afro-estadunidense, com as quais ele vai simultaneamente não somente se embevecer, mas também ter ímpetos de branquear suas manifestações, como no caso do ragtime" (OLIVEIRA, 2015, p.301 - grifos do autor).

Essa aventura vivenciada pelo protagonista de Johnson se dá frente a um cenário de constantes deslocamentos movimento diaspórico - pelos Estados Unidos e Europa. A esse respeito, Thomas Bonnici destaca que a "diáspora refere-se ao trauma coletivo de um povo que voluntária ou involuntariamente saiu ou foi banido da sua terra e, vivendo num lugar estranho, sente-se desenraizado de sua cultura e de seu lar" (2009, p.30). Em vista disso, também propomos aqui a extensão dessa noção coletiva para a situação individual do protagonista sem nome de Johnson, já que o seu trânsito por espaços geográficos e emocionais é suficientemente emblemático em Autobiografia, para desvelar um protagonista deslocado, um sujeito desenraizado e amarguradamente marcado por todo o trauma que se deriva desse processo.

$\mathrm{Na}$ narrativa de Johnson, vemos que o processo de deslocamento constitui-se como um exílio voluntário, 
visto que o sujeito migra em busca de melhores condições de vida e para se esquivar das crueldades advindas das políticas de segregação. Edward Said ressalta que "o exílio tem origem na velha prática do banimento" (2003, p.54). De fato, em Autobiografia, o protagonista não é banido de sua cidade natal. Entretanto, ele não é bem visto pela sociedade por ser filho de um homem branco com uma mulher negra. Desse modo, problemas lhe seriam criados até que ele saísse de "cena", principalmente porque a sociedade daquela época tinha por hábito silenciar tudo o que se relacionasse ao universo afro-estadunidense.

Esse deslocamento (auto)imposto coloca em conflito a identidade do sujeito e a sua tradição cultural. Nas circunstâncias em que o sujeito permanece em migração, novas experiências se descortinam para ele, o que promove a sua imersão em diferentes contextos políticos e culturais, que acabam influenciando a construção da(s) sua(s) nova(s) identidade(s). Com referência a isso, Stuart Hall (2003) nos fala que:

Os elementos da 'tradição' não só podem ser reorganizados para se articular as diferentes práticas e posições e adquirir um novo significado e relevância. Com frequência, também, a luta cultural surge mais intensamente naquele ponto onde tradições distintas e antagônicas se encontram ou 
se cruzam. Elas procuram destacar uma forma cultural de sua inserção em uma nova tradição, conferindo-lhe uma nova ressonância ou valência cultural. (p.260)

Mesmo tendo suas crenças, costumes, tradições e sua bagagem cultural totalmente formada, ocorre que o sujeito em deslocamento muito frequentemente constrói uma identidade multicultural, tomando cuidado para que a sua cultura não seja negada pelo outro. Em Autobiografia, o protagonista se vale da língua e da música, que permitem a ele transitar pelos espaços culturais distintos com os quais passa a se defrontar pelo périplo que se vê obrigado a empreender.

Esse contato com diferentes culturas faz emergir uma crise identitária no narrador-personagem de Johnson. Ele agora faz parte de inúmeras culturas. Ele é descendente de negros, seus traços fenotípicos são de uma pessoa branca, ele vive um período considerável com uma comunidade cubana no sul dos EUA, aprende espanhol e passa a trabalhar numa fábrica de charutos com membros desse grupo, com quem faz amizade. Acompanhado por uma personagem misteriosa que ele chama de "meu milionário", ele também reside por meses em Paris, Londres e Berlim, onde tem experiências de emancipação, maior respeito por parte dos outros e crescimento de autoestima que 
as terras estadunidenses jamais Ihe teriam proporcionado; tudo isso enquanto é patrocinado por esse benfeitor, que o remunera pelas apresentações ao piano que ele executa particularmente para esse senhor ou para os seus grupos de amigos. Não obstante esse interregno de relativa zona de conforto pacífica, o clássico questionamento sobre quem ele era passa a ecoar fortemente na vida e na mente do protagonista.

Esse questionamento é originado pelos traumas da segregação racial, pela diáspora e pelos conflitos entre culturas. O protagonista é fruto desses conflitos e da "fragmentação", que se dá como consequência das opressões, do silenciamento, do ímpeto de negação da sua porção de identidade afroestadunidense e da impossibilidade de usufruir plenamente dos seus direitos culturais, políticose sociais como homem de cor, que são problematizados quando ele se vê perdido num entrelugar traumático. Como resultado desse turbilhão, a identidade unificada é desconstruída e cede lugar à multiplicidade de identidades. Essas diversas identidades conflitam entre si, mas também se hibridizam e formam uma identidade multicultural composta por inúmeras facetas.

\section{CONSIDERAÇÕES FINAIS}

Apesar do caráter ficcional, Autobiografia de um ex-negro baseou-se no drama de pessoas reais, lugares e situações vivenciadas por James Weldon Johnson, demonstrando, 
assim, um perfeito roman à clef, pois descreve "episódios da vida real sob uma aparência de ficção. Em geral, os autores buscam, com isso, o efeito satírico, para evitar contendas envolvendo pessoas e situações retratadas ou, ainda, para tratar temas controversos sem o caráter de um libelo" (FRIZERO, 2010, p.191). Esse caráter confessional e até mesmo (auto)biográfico dado pelo escritor à narrativa ressalta a importância do romance por ser concebido por um escritor afro-estadunidense e por obter grande sucesso com o seu relançamento (1927) durante os anos de ebulição da Renascença do Harlem.

A narrativa de Johnson é composta por uma mistura de gêneros, além de diferentes utilizações de discurso. Há a narração linear da vida do narrador-personagem, de sua infância como negro à fase adulta, suas peripécias e aventuras, seu trânsito por diferentes culturas e seus conflitos identitários. Há, também, a presença de um discurso político e até mesmo filosófico. O narrador reflete e analisa o seu tempo e a sua própria condição humana, conjetura, também, sobre as políticas de segregação impostas à população negra. Há, ainda, uma longa reflexão contida nas linhas do romance sobre a identidade desse narrador.

Ao longo de todo o romance, observamos um processo de busca e construção identitária. O protagonista de Johnson 
constrói sua identidade frente a um movimento diaspórico, além de constantes fragmentações ocorridas ao longo de sua vida. Como consequência final disso, temos um indivíduo híbrido. O termo "híbrido" foi cunhado originalmente por botânicos, "para se referir a uma variedade de planta adaptada a um determinado ambiente de seleção natural" (BURKE, 2008, p.53). Carlos Ceia, em seu dicionário de termos literários, define o híbrido como aquilo que "participa de dois ou mais conjuntos, gêneros ou estilos. Considera-se híbrida a composição de dois elementos diversos anomalamente reunidos para originar um terceiro elemento que pode ter as características dos dois primeiros reforçadas ou reduzidas" (2009, p.1).

Peter Burke (2008, p.36) destaca que os indivíduos híbridos podem ser "os que já nasceram nesta situação por suas mães e pais serem originários de culturas diferentes, quer os que se viram nela mais tarde, de bom grado ou não, por terem sido, por exemplo, convertidos ou capturados". Corroborando essa tese, Burke (2008) recorre à famosa expressão do líder e ativista negro W. B. Du Bois, para esclarecer que uma vida entre diferentes culturas resulta em uma "consciência dúplice".

O narrador-personagem da obra de Johnson é um sujeito que se encontra num entrelugar de diferentes culturas e etnias. Ele é fenotipicamente branco, mas tem ascendência negra. Ele nasceu em uma pequena cidade da Geórgia, 
mas não tem nenhuma raiz lá. Ele é um cidadão estadunidense, mas é visto como um pária; um intruso por não pertencer "de fato" a um determinado grupo social ou étnico, podendose afirmar que ele se torna vítima de uma sutileza cruel do segregacionismo estadunidense da época, na medida em que a ele é negado um lugar de pertencimento até mesmo por muitos dos grupos de pessoas fenotipicamente negras, uma vez que ele é um negro "diferente".

Como desdobramento disso, o narrador opta pelo passing. Em virtude da sua cor de pele, ele opta por se passar por um homem branco, já que a questão racial é associada à ascendência familiar, e não à aparência física. Ao escolher esse caminho, o protagonista opta pelo bem-estar pessoal e financeiro, pois, assim fazendo, "sua aparência de homem branco passou a ser o escudo mais perfeito" (OLIVEIRA, 2015, p.311).

As vantagens que ele colhe por essa escolha se sobressaem a qualquer arrependimento por apagar sua ascendência negra. Mesmo aderindo ao passing, o narrador ainda é um indivíduo híbrido e multicultural, mas também infeliz e traumatizado. A escolha por uma identidade não exclui as demais, uma vez que elas permanecem nele em um constante conflito, mesmo que o Outro veja somente 
um lado desse sujeito - o lado branco e de sucesso financeiro, prestigioso aos olhos da sociedade preconceituosa. O racismo e as políticas segregacionistas que vitimaram e produziram traumas e sofrimentos ao protagonista de Johnson nos anos da Reconstrução geraram conflitos e marcas que, infelizmente, ainda permanecem nos dias atuais. Em suma, todos esses elementos provocam uma série de conflitos e problemas que marcam a existência do narrador, ocasionando a necessidade de que ele se desfaça de sua herança cultural e genética africana.

\section{REFERÊNCIAS}

BETHENCOURT, Francisco (2018). Racismos: das cruzadas ao século XX. São Paulo: Companhia das Letras.

BURKE, Peter (2008). Hibridismo cultural. São Paulo: Unisinos - Editora da Universidade do Vale do Rio dos Sinos.

BONNICl, Thomas (2009). Resistência e intervenção nas literaturas pós-coloniais. Maringá: EDUEM - Editora da Universidade Estadual de Maringá.

CEIA, Carlos (2009). E-Dicionário de termos literários. In http://edtl.fcsh. unl.pt/encyclopedia/hibrido/ Acesso em 19.Nov.2018.

FRIZERO, Robertson (2010). “Johnson, um pioneiro". In: JOHNSON, James Weldon. Autobiografia de um ex-negro. Robertson Frizero (Trad.). Porto Alegre: 8inverso. p.187-191.

HALL, Stuart (1998). A identidade cultural na pós-modernidade. Rio de Janeiro: DP\&A, 1998.

(2003). Da diáspora: identidades e mediações culturais. Belo Horizonte: Editora da UFMG. 
HATTNHER, Álvaro Luiz (1992). A expressão da negritude na poesia de Langston Hughes e Solano Trindade. (Dissertação de mestrado - Estudos Literários) - Universidade Estadual Paulista Júlio de Mesquita Filho, São José do Rio Preto.

JOHNSON, James Weldon (2010). Autobiografia de um ex-negro. Robertson Frizero (Trad.). Porto Alegre: 8inverso.

KARNAL, Leandro (2007). "A formação da nação". In: KARNAL, Leandro et al. História dos Estados Unidos: das origens ao século XXI. São Paulo: Contexto. p.23-98.

OLIVEIRA, Luiz Manoel da Silva (2015). "Sutilezas cruéis das políticas estadunidenses do racismo e da segregação em Autobiografia de um exnegro, de James Weldon Johnson". In: ASSUNÇÃO, Antônio Luís et al. As letras da política. Rio de Janeiro: Mauad X. p.295-312.

PACHECO, Josephine Fenneli (1983). O problema do racismo nos Estados Unidos. Curitiba: Editora Universidade Federal do Paraná.

SAID, Edward (2003). Reflexões sobre o exílio e outros ensaios. São Paulo: Companhia das Letras.

TOMÉ, Pedro (2016). Traduzindo Langston Hughes- do texto à voz, da voz ao texto. Cadernos de Literatura em Tradução, 16(1), 117-130.

Leonardo Júnio Sobrinho Rosa é Mestrando em Letras da UFSJ. Licenciado em Filosofia pela Universidade Federal de São João del-Rei (2018). E-mail: leonardo_junio@live.com

Luiz Manoel da Silva Oliveira Doutor em Letras (Ciência da Literatura/ Literatura Comparada) pela Universidade Federal do Rio de Janeiro (2007). Mestre em Literaturas de Língua Inglesa pela Universidade do Estado do Rio de Janeiro (2003). Fez estágio pós-doutoral no Programa de Pós-Graduação em Estudos Literários da Universidade Federal de Minas Gerais, de 15/02/2016 a 14/02/2017. Especialista em Literaturas de Língua Inglesa pela Universidade do Estado do Rio de Janeiro (1997). Licenciado em Letras (Inglês e Literaturas de Língua Portuguesa) pela Universidade do Estado do Rio de Janeiro (1983). Atualmente é professor Associado 
na Universidade Federal de São João del-Rei, membro do corpo docente e coordenador do PROMEL - Programa de Mestrado em Letras da UFSJ. E-mail: luizmanoel@ufsj.edu.br

Recebido em 30 de novembro de 2018. Aprovado em 11 de fevereiro de 2019. 